\title{
A inserção social através de telecentros: notas de pesquisa
}

\author{
Marta Pinheiro Aun \\ Mauro Araújo Câmara*
}

\begin{abstract}
Resumo A Sociedade da Informação estabelece novas estratégias de inclusão e um novo tipo de construção social. O artigo analisa os telecentros como estruturas de inserção social, permeadas pela virtualidade, sem o contato face a face. A inclusão de povos marginalizados pode ser feita via sistemas informacionais que, compartilhados, superam barreiras de língua e gaps tecnológicos. Por meio de pesquisa qualitativa, realizou-se um estudo em distritos de Minas Gerais, onde foram instalados telecentros como proposta de inclusão digital. Resultados preliminares apontam a emergência de traços contemporâneos a partir de novos hábitos e costumes.
\end{abstract}

Palavras-chave sociedade da informação, inclusão social, telecentros, sustentabilidade, software livre

\begin{abstract}
The Information Society establishes new strategies of inclusion and a new type of social construction. The article analyzes the telecentres as structures of social insertion, based on virtual, without the face-to-face contact. The inclusion of kept out of society peoples can be made by shared informational systems, surpassing barriers of language and technological gaps. Through qualitative research, a study was fulfilled in districts of Minas Gerais, where telecentres had been installed as proposal of digital inclusion. Preliminary results indicate to the emergency of traces contemporaries from new habits and customs.
\end{abstract}

Keywords information society, telecentres, social inclusion, sustainability, free software

\section{Introdução}

A emergência da Sociedade da Informação manifesta-se por um conjunto de transformações profundas nas mais diferentes dimensões. A velocidade das mudanças, o volume de informações disponíveis e a diversidade e dependência tecnológica cresceram assustadoramente. A emergência de uma economia informacional global, facilitada pelo desenvolvimento de tecnologias e a criação de redes informacionais pode trazer muitos benefícios, mas apresenta dificuldades para os diferentes segmentos sociais:

\footnotetext{
*

* Marta Pinheiro Aun é Doutora em Ciência da Informação - IBICT/CNPq-ECO-UFRJ; Mauro Araújo Câmara é Mestre em Ciência da Informação - PPGCI/ECI-UFMG
} 
Entendemos que quando ocorrem problemas de transição de um sistema produtivo, também são grandes as dificuldades do sistema econômico, institucional, legal e social em adaptar-se. Tais dificuldades são consideradas tão importantes e radicais quanto as próprias inovações técnicas em que se baseiam. Mostra-se particularmente importante que diferentes segmentos das distintas sociedades conheçam e possam participar da decisão de quais caminhos trilhar, uma vez que possivelmente encontra-se em questão o estilo dominante por uma fase inteira de crescimento e desenvolvimento econômico. (LASTRES; FERRAZ, 1999. p. 54).

Sendo seu principal insumo e o principal produto, a informação é indutora da dependência das novas tecnologias de informação e de aprendizado contínuo. A sociedade da informação é então caracterizada pelas redes e por sua versatilidade, capacidade de armazenamento e de deslocamento em tempo real, tornando-se conceito popularizado a partir da década de 90 e que, basicamente, se caracteriza discursivamente pelo esforço dos governos de preservar uma sustentabilidade econômico-social, pois ela surge com o vislumbrar de novas oportunidades. É esperado o acesso e concessão de recursos informacionais para todos e de coesão social para as diferentes regiões do mundo.

Mas sabe-se que uma verdadeira integração não se faz só no âmbito dos grandes negócios. A inclusão de povos e países marginalizados é dependente de vontade política e pode ser feita via acesso a sistemas informacionais compartilhados capazes de superar barreiras de língua e gaps tecnológicos. Não se trata de garantir simples sobrevivência dentro do sistema, mas incentivar um novo tipo de relação produtiva, tendo nos ainda excluídos os agentes principais. Enfatiza-se a relevância das redes de compartilhamento propiciadoras da inclusão na economia atual, um instrumento de acesso às informações e troca de experiências em nível mundial. (LEFEBVRE, 2004; NÉROT, 2004).

Buscamos no desenvolvimento de uma pesquisa que analisou a implantação dos telecentros em uma região rural de Minas Gerais, verificar se o sistema implantado vem auxiliar o desenvolvimento de novas relações produtivas como parte da inserção social no ambiente sócioinformacional da sociedade da informação. Para tal, pesquisamos o nível de participação política nesse processo, a influência e emergência da tecnologia na vida social, os novos problemas informacionais e sua interferência à liberdade de acesso às redes e à informação.

\section{O impasse dos Estados e a aplicação das tecnologias}

Com a generalização do uso de tecnologias e redes de informação e de comunicação, a informatização da sociedade conduz a mudanças e exerce pressões sobre os Estados alterando suas formas de atuar. "O Estado parece ter se tornado figura fragilizada, envolvido pela gama de movimentos imprevisíveis da esfera econômica, sendo rotulado de uma máquina 'pesada' e 'inchada' até mesmo por seus próprios governantes.” (AUN, 2001, p. 60-61).

A sociedade da informação não é um sistema estável, pois está sujeita a um poderoso agente de transformação dos homens e das estruturas sociais: a informação (ARAÚJO, 1994). Não há 
como a Sociedade da Informação ser homogênea e não se consegue atingi-la sem políticas que coordenem a cultura informacional requerida.

A melhor estratégia de gestão condutora ao desenvolvimento e de participação compartilhada aos conteúdos é estabelecida por políticas governamentais balizadoras e condutoras ao sucesso das iniciativas de autogestão para o desenvolvimento sustentável e descentralizado. Espera-se, como projeto político, a relevância de uma formação política e cultural voltada para a autogestão. Daí a importância de fortalecer as redes técnicas que permitem que cada comunidade se integre ao mundo, mas de acordo com suas necessidades e especificidades.

O conhecimento e as condições para sua criação e circulação são o ponto de partida para qualquer desenvolvimento saudável, o que não se dá desvinculado da cultura local. Esse vínculo é o que direciona o esforço coletivo inicial e auxilia na manutenção da identidade dessas comunidades, independente da natureza das mesmas. Se as políticas não cuidarem desses aspectos já amplamente discutidos, a presença concentrada de tecnologias de certa forma restringirá vocabulário e terminologias. E outros pontos de acesso ao conhecimento devem ser considerados no desenvolvimento de diferentes comunidades.

Assim, buscamos chamar a atenção para quatro aspectos fundamentais quando se trata de aplicação de tecnologias ou desenvolvimento de programas visando à inclusão digital: (i) o entendimento das especificidades locais ou regionais, assim como do conteúdo informacional que as caracteriza; (ii) a necessidade de estratégias distintas para os diversos tipos de sociedades (sobrevivência, inovação); (iii) a identificação, estudo e compartilhamento dos conhecimentos tácitos envolvidos; e (iv) a identidade e os valores sócio-culturais das comunidades como um todo (AUN; ARANTES; KROEFF, 2005).

Os dois primeiros aspectos são fundamentais para a eficácia dos programas de implantação de telecentros, para não se lançar mão de ações que firam os princípios e a identidade da comunidade. Os dois subseqüentes, a preocupação efetiva com os conhecimentos tácitos e valores sócio-culturais revelam um amplo campo de aplicação desses programas no desenvolvimento econômico e social de diferentes comunidades, ao garantir a argamassa necessária à estruturação de desenvolvimento para todos.

As tecnologias e seus usos para diferentes setores e países desenvolvidos já estão suficientemente maduras a ponto de evoluir por elas mesmas, mas a concentração e a propriedade da disseminação favorecem a desinformação, facilita a manipulação por uma homogeneização cultural que afeta a liberdade para as sociedades em desenvolvimento.

Quanto mais pensarmos em social computing, de forma descentralizada, a partir do enfoque em pessoas e das redes que se estabelecem entre e através delas, melhor seria a nossa realidade, pois

A mutação [...] é radical. Ela é profunda também em suas proporções, isto é, no nível das grandezas envolvidas, por sua amplitude e por sua universalidade em escala planetária. Ela é enfim radical, pois se trata de uma mutação estrutural, ou seja, de um rearranjo de certos elementos que são conservados, mas cuja função sofreu uma reviravolta como, por exemplo, o papel do trabalho operário, o papel do conhecimento, a função do mercado, a relação com a técnica. (MOULIER-BOUTANG, 2003, p. 38). 
$\mathrm{Na}$ centralidade das mudanças, importante se faz a coordenação de recursos e esforços em direção à educação. A educação do indivíduo, nessa sociedade do conhecimento, torna-se fator de extrema importância. Para Delors "[...] face aos múltiplos desafios do futuro, a educação surge como um trunfo indispensável à humanidade na construção dos ideais da paz, da liberdade e da justiça social. Só a educação conduzirá a um desenvolvimento humano mais harmonioso, mais autêntico, de modo a fazer recuar a pobreza, a exclusão social, as incompreensões, as opressões, as guerras [...] (DELORS, 2000).

Há verdadeiramente o estabelecimento de uma nova ordem de valor e de demanda de capacitação com maiores dificuldades de se estabelecer um crescimento econômico mais equilibrado, o que torna pertinente a observação de Schweinberger (2000). Ele alerta para o fato de que todo o avanço conseguido pela humanidade em pleno século XXI não conseguiu resolver plenamente questões básicas seculares como acesso à saúde, à educação, à habitação, ao emprego e à seguridade social e que tais questões estão, na verdade, se agravando apesar de toda centralidade na informação e sua comunicação.

A massa de excluídos e a população abaixo da linha de pobreza nos países pobres do Sul vêm se incrementando em termos absolutos e relativos. Nos países ricos do Norte, o contingente de desempregados está crescendo e os bolsões de pobreza estão se ampliando. A esses se somam novos problemas, como a crescente poluição do meio ambiente, dilapidação dos recursos naturais, insegurança pública e instabilidade econômica e social. (SCHWEINBERGER, 2000, p. 83-84).

A economia ao intensificar a colocação de modelos que concentram riqueza de um lado e pobreza de outro usou da concentração tecnológica. O Brasil ainda não conseguiu achar o caminho de seu desenvolvimento tendo seu cotidiano marcado pela pobreza, concentração de renda e falta de empregabilidade. O desemprego e o conseqüente aprofundamento dos gaps de renda entre os estratos sociais e das desigualdades na habilitação de classes menos favorecidas para funções ainda empregadoras, têm crescido de forma alarmante em todo o mundo, inclusive nas sociedades economicamente desenvolvidas $\mathrm{O}$ que nos coloca a pensar em alternativas ao desenvolvimento, já que o processo de globalização valorizado em constante ufanismo não possibilitou a inserção das economias mais pobres na era informacional.

A precarização do salariado expõe uma parte dos trabalhadores dependentes à aléa do mercado e, portanto à sua disciplina que tem que ser interiorizada em forma de gestão do risco pessoal e da incerteza. Esses trabalhadores passam assim a experimentar as agruras do estatuto de trabalhador independente. (MOULIER-BOUTANG, 2003, p. 44).

Do processo de globalização herdamos o marketing da cultura digital. Somos campeões em número de celulares e acessos a serviços como o Orkut, mas tudo isso de forma concentrada, o que não tem ajudado no nosso desenvolvimento em questões básicas de sobrevivência.

Desde o início da década de 90 assistimos a diversificadas decisões políticas visando à criação de sociedades da informação, mas dentre essas decisões, a necessidade de se configurar uma 
política de informação nos moldes requeridos pela Sociedade da Informação não está ainda mundialmente reconhecida (AUN, 2003).

Segundo Nérot (2004), não será utopia uma aplicação humanitária das tecnologias exigindo apenas vontade política que inspire soluções técnicas adaptadas ao acesso e ao uso dos diferentes usuários das redes. $\mathrm{O}$ grande desafio seria o da interação do tecnológico e do institucional (nação, povo, território, cultura, costumes, memórias, política, economia).

\section{Influência da urgência}

A questão da urgência e de programas emergenciais de inclusão à sociedade da informação está normalmente associada às TICs e é vista por determinados autores com reserva. Giddens (1991) e Monnoyer-Smith (1998), por exemplo, apontam que a representação do tempo, acelerada pelas técnicas, seja uma das conseqüências da modernidade, influenciando sociedades e seus governos a darem uma conotação obsessiva ao fator tempo. Isto, para Monnoyer-Smith (1998), vem gerando no modelo ocidental de cultura temporal duas características:

a) o tempo agora é tomado como termo de eficácia e eficiência. ${ }^{1}$

b) a rapidez é encorajada e valorizada. A rapidez de respostas e de ações passa a ser elemento chave da competitividade das empresas.

Como conseqüência desta supervalorização do tempo surge a ideologia da urgência que aparece claramente no nível político como uma forma de ação-resposta às crises crônicas enfrentadas pelos governos. Quando não se fala nos discursos em urgência, emergência, fala-se de atraso e sempre do atraso técnico (gestão da técnica) ou de domínio da técnica (gestão técnica do sócio-cultural).

Monnoyer-Smith (1998) argumenta que a urgência vem para preencher um vazio conceitual, próprio à transição e assim cita Aubert (1997): "A urgência se presta a dissimular a perda de significado que afeta nossas sociedades e se traduz, entre outras coisas, pela impossibilidade de se estabelecer uma representação de um futuro significativo, satisfatório e coerente".

Para Santos (2004), a multiplicidade de tempos de diferentes territórios é reduzida a um tempo linear.

[...] assenta na monocultura do tempo linear, a idéia de que a história tem sentido e direção únicos e conhecidos. Esse sentido e essa direção têm sido formulados de diversas formas nos últimos duzentos anos: progresso, revolução, modernização, desenvolvimento, crescimento, globalização. Comum a todas estas formulações é a idéia de que o tempo é linear e que, na frente do tempo seguem os países centrais do sistema mundial e, com eles, os conhecimentos, as instituições e as formas de sociabilidade que neles dominam. Esta lógica produz não-existência declarando atrasado tudo que, segundo a norma temporal, é assimétrico em relação ao que é declarado avançado. É nos termos desta lógica que a

\footnotetext{
${ }^{1} \mathrm{O}$ autor atribui esta particularidade à invasão da lógica de mercado em todas as esferas da economia e da sociedade.
} 
modernidade ocidental produz a não contemporaneidade do contemporâneo, a idéia de que a simultaneidade esconde as assimetrias dos tempos históricos que nela convergem [...] (SANTOS, 2004, p. 787).

A maioria dos programas de inclusão digital preocupa-se com a distribuição e investimento em infra-estrutura técnica. Mas não visa preparar os usuários para o desenvolvimento de uma inteligência que usa a técnica para definir canais no interior das redes que o mantenham informado (NÉROT, 2004).

Evidentemente que o ritmo e a orientação do desenvolvimento tecnológico, assim como suas relações com os requerimentos da sociedade da informação dependem de decisões políticas, tanto públicas como privadas. Surgem novos serviços que têm forte repercussão na vida dos cidadãos, obrigados a novas capacitações e instados a absorver uma variedade de fluxos de informação que não conhecem mais fronteiras.

\section{Reducionismo nas políticas e liberdade de acesso}

A sociedade em redes abre espaço para o reforço de configurações econômicas mais localizadas e transformadas por um processo de comunicação informacional contínua. Entretanto, esta dinâmica impõe algumas conseqüências pouco desejadas. A maior delas, observada atualmente, é a exclusão de regiões inteiras e mesmo continentes, o que nos remete à necessidade real de se considerar questões locais e seus indicadores para garantir a emergência de novas economias como a brasileira. Tentando vencer essas dificuldades é que surgem mecanismos de proteção, assim como novas organizações que, com ou sem apoio dos governos, tentam ajudar a dissipar essas disfunções e bloqueios. Emerge em todo o país, por meio de iniciativas municipais, estaduais, federais e de organizações da sociedade civil, programas de inclusão social de forma ampliada a atender os requisitos da sociedade da informação.

Para Benkler (2003), inclusão social representa um bem comum, ou seja, um direito de todos. Alguns bens comuns recebemos gratuitamente da natureza, outros são produtos coletivos colocados pela criatividade dos seres humanos. A informação é um bem público no seu verdadeiro sentido. A sociedade da informação através da instalação do paradigma das tecnologias de informação desperta primeiramente para a necessidade de usufruir da comunicação à distância. Assim o direito à comunicação mediada por computadores passa a bem comum pelo direito que todos temos em participar, receber e aproveitar os benefícios da sociedade informacional.

Para facilitar o acesso e sua multiplicação os governos têm como base a ideologia democrática da rede. Também organizações sem fins lucrativos utilizam a web para fornecer informações de bem público. Neste esforço, observa-se que o seu domínio e potencial de acesso não seriam viabilizados para grandes contingentes de pessoas se a linguagem básica da Internet fosse "aprisionada", ou seja, uma linguagem pertencente a um sistema operacional proprietário, criando monopólio e dependência de usuários. Além de maior compartilhamento de informação a tecnologia digital não aprisionada permite a distribuição da informação a um baixo custo unitário possibilitando oportunidade e abrangência maior em seu uso. (SILVEIRA, 2003).

Amplamente discutido e marcado por intenso e sistemático trabalho do governo brasileiro nessa direção, através do Instituto Nacional de Tecnologia da Informação - ITI, o tema inclusão digital tem sido levado como bandeira para o processo de inclusão social dos cidadãos e divulgação das 
ações governamentais focadas no desenvolvimento tecnológico. A necessidade de transformar a inclusão digital em política pública tornou-se de fundamental importância em combinação com a iniciativa privada, organizações não-governamentais e administração pública federal, estadual e municipal, sendo essa última esfera a mais importante no sentido de possuir maior capacidade de influência e penetração nas comunidades das diversas regiões do país (SILVEIRA, 2003, p. 30).

\section{Evolução dos problemas informacionais}

O telecentro como estrutura viável para a disseminação tecnológica no processo de inclusão informacional e, portanto, como objeto do trabalho de pesquisa, merece melhor análise, estudo e avaliação de seus impactos dada a recentidade de seu surgimento, posto que "o enfoque contemporâneo busca a valorização das questões sociais da informação, valorizando os sujeitos sociais, como agentes produtores e consumidores de informação." (SARACEVIC, 1996, p. 47). Borges (2002) observa que as tendências emergentes colocam o indivíduo como agente ativo na construção do significado das situações com as quais se depara.

$\mathrm{O}$ indivíduo deixa de ser considerado como receptor passivo de informação, passando a ativo, na interação entre a estrutura de informação e a sua estrutura conceitual própria. Os focos deixam de ser os sistemas e a tecnologia da informação, passando aos usuários como indivíduos em contínua interação com o meio e com outros indivíduos. (BORGES, 2002, p. 39).

Diante das relações sociais que, mesmo na busca do conhecimento ou da informação, "as novas práticas baseadas no uso da tecnologia passam a se realizar pela impessoalidade", como defende Giddens (1991, p. 27-37) em sua teoria das relações sociais, torna-se importante destacar nessa mudança a participação do indivíduo. Entende que, na modernidade, as práticas sociais são "constantemente examinadas e reformuladas à luz da informação renovada sobre essas próprias práticas, alterando assim constitutivamente seu caráter". Idéia reforçada por Paim e Nehmy (1998), essas relações, "ao invés de se basearem de modo dominante em sistemas locais de relações interpessoais, deslocaram-se para um tipo de relação baseada em anonimato e distanciamento espaço-temporal" e complementam: "Na atualidade, tempo e espaço não mais coincidem, havendo o fomento de relações entre ausentes, localmente distantes de qualquer situação dada ou interação face a face" (PAIM; NEHMY, 1998: 82).

González de Gómez (2004) alerta para os processos de comunicação que não absorvem fatores endógenos às práticas sociais tais como cultura, memória e sociedade. Para a autora as relações em rede correm o risco de se estabelecer uma diáspora digital, onde o "internauta", como um imigrante, abandona a casa da sua linguagem, seus hábitos de interlocução face a face, sendo obrigado a construir uma autonomia informacional em terras virtuais. Salienta então a importância da tradução. A negociação com as diferenças onde, em rede, é possível redefinir, aperfeiçoar, a partir de contextos de experiências e de ação.

A inclusão dos novos instrumentos inseridos pelo paradigma técno-econômico das tecnologias de informação dificulta o processo de tradução exigindo a observação de suas variáveis: 
necessidade de filtros específicos, gestão diferenciada de conteúdos informacionais e apropriação adequada da tecnologia, gerando novas exigências de capacitação para inserção profissional e coletiva. A centralidade no recurso informação requer uma nova gestão ao objetivar a criação de novas estruturas e cultura que facilite o compartilhamento dessa informação.

Com o deslocamento da atenção dos governos para as necessidades de adaptação às novas exigências das tecnologias de informação e comunicação, cresce, em meados dos anos 90 a adoção de telecentros comunitários como ferramenta de desenvolvimento para populações menos favorecidas (MENOU; DAY, 2005). Assim têm sido implementados os telecentros: "centro de atendimento coletivo que oferece serviços, em regime de parcerias, aos diversos segmentos da sociedade da área urbana e da área rural, utilizando facilidades de telecomunicações e de informática e atuando como agente de desenvolvimento econômico, político e sócio-cultural." (DARELLI, 2003, p. 26).

Destaca-se que esses tornam-se ambientes ricos de pesquisas que visam a inclusão social, quando se tem por pressuposto norteador que essa inclusão pode ser proporcionada a partir das práticas informacionais em que as interações ocorram em contextos adequados, tendo a tecnologia como instrumental de suporte.

Para Menou (2002), o ponto central do debate sobre a inclusão digital não deve ser qual o melhor caminho para trazer as TIC's para as populações mais pobres, mas qual o melhor caminho para os pobres tirarem proveito das TIC's em benefício de seu crescimento. Para que se atinja esta nova cultura requerida é necessário investimento no mix informacional, ${ }^{2}$ que permita a todos participar ao modificar, comentar, completar o conteúdo perpassado por essas tecnologias, o que implica na definição de políticas de educação e de informação. Essas políticas devem partir do reconhecimento de que os problemas devem ser tratados de forma diferenciada por retratarem mundos organizacionais também diferenciados (MONNOYER-SMITH, 1998).

Buscando avaliar a atuação dos programas de telecentros como iniciativas de desenvolvimento econômico, político e sócio-cultural, escolhemos um programa desenvolvido pela ONG Gemas da Terra, aplicado em área rural bastante carente de recursos, porém com a cultura ainda preservada.

\section{O Projeto Gemas da Terra: iniciativa de inclusão social}

No Brasil, são inúmeras as comunidades que perderam seu potencial de sustentabilidade, anteriormente ligado às atividades primárias que podem, pelo acesso a conteúdos informacionais bem direcionados, reencontrar o caminho de sua sustentabilidade. Este é um estudo de caso em distritos do interior de Minas Gerais, onde já foram instalados telecentros como estrutura tecnológica de inserção social. O programa analisado, Gemas da Terra, tem como missão facilitar a criação de telecentros livres em comunidades rurais brasileiras e promover a sua integração ao movimento global de inclusão digital.

Concebido a partir do ano de 2003, o programa implantou o projeto piloto em cinco comunidades rurais na região central do Estado, conhecida como Alto Vale do Jequitinhonha

\footnotetext{
${ }^{2}$ Mix informacional: existência de infra-estrutura educacional, disponibilidade de serviços de informação e grau de interação tácita.
} 
onde, por muitos anos, fez parte do caminho que transportava ouro e diamante extraído da região para a corte real no século XVIII. As comunidades foram escolhidas com base no seu perfil demográfico (entre 1000 e 2500 habitantes), nível de organização através de associações e identificação de um grupo de voluntários interessados em trabalhar no projeto.

Foram contempladas no projeto piloto as localidades de São Gonçalo do Rio das Pedras, Milho Verde, Tombadouro, Conselheiro Mata e Rodeador. O acesso a todas elas só é possível por estradas não-pavimentadas e a ligação com cidades maiores da região é suportada por linha de ônibus que circula uma vez por dia. Em temporada de chuvas o acesso é extremamente prejudicado, podendo passar vários dias sem transporte.

Tendo como referência o Livro de Receitas do Telecentro Comunitário para a África (JENSEN; ESTERHUYSEN, 2001), trabalho desenvolvido pela Organização Educacional, Científica e Cultural das Nações Unidas, o objetivo do programa é possibilitar a criação de estruturas de telecentro, proporcionando o acesso à rede Internet e torná-los auto-sustentáveis e independentes, permitindo assim que a própria comunidade identifique suas demandas e determinem as ações necessárias para o desenvolvimento local com o uso da tecnologia. O programa utiliza a metodologia de realizar a capacitação de moradores da própria comunidade e torná-los multiplicadores de conhecimento. Essa capacitação visa o entendimento da filosofia do programa bem como o aprendizado sobre os equipamentos.

O destaque apresentado pelo coordenador do programa está relacionado à questão de sustentabilidade. Diferentemente de propostas governamentais, ele entende que as estruturas dos telecentros devem ser amparadas na idéia de auto-sustentabilidade desde sua concepção. Nesse aspecto, destaca que o principal objetivo na metodologia adotada é apoiar as comunidades rurais na busca da auto-sustentação econômica e política. Para isso, foi desenvolvido um modelo de conscientização e apoio ao auto-crescimento da comunidade pela valorização da cultura e da economia local. O modelo Gemas da Terra prepara a comunidade para gerir seu próprio telecentro, enquanto busca apoio de entidades externas para garantir a ajuda inicial necessária para sua implementação.

O telecentro de São Gonçalo do Rio das Pedras está localizado na região central da comunidade e compartilha o espaço com outras atividades da Associação Comunitária, dentre elas, tapeçaria, trabalhos educativos para crianças e reuniões de seus membros. Utiliza uma sala de aproximadamente $15 \mathrm{~m}^{2}$ e nela foram instalados os equipamentos do projeto piloto sendo: dois microcomputadores utilizando software livre e uma impressora multifuncional, além dos equipamentos de rede e modem de conexão à antena de satélite.

Funciona com a participação de voluntários que fizeram o curso de capacitação do projeto e oferece à comunidade o acesso à Internet, serviço de impressão, digitação e fotocópia. Os serviços oferecidos são cobrados, a preços compatíveis com a realidade local e a receita é revertida para aquisição de material de escritório, material de limpeza, papel e tinta para impressora, garantindo pela própria comunidade a sua continuidade. A metodologia aplicada pelo Gemas da Terra espera que as comunidades encontrem seus próprios meios de organização e de sobrevivência.

As principais demandas apresentadas pela comunidade no uso do telecentro relacionam-se a: pesquisa escolar, uso de correio eletrônico, informações sobre artesanato e receitas culinárias. Já houve por parte dos voluntários a busca por informações sobre atividades para crianças, pesquisa sobre reciclagem de lixo, acesso à conta bancária, cadastro de CPF e edição de textos. Os voluntários entendem que o telecentro "serve para integrar mais a população" e que "gostariam de fazer trabalhos voltados para a comunidade", atividades que estivessem direcionadas para o 
benefício das pessoas. Foi citada a idéia de "fazer download de filmes, gravar em $c d$-rom e exibir para a comunidade, na praça principal, como forma de reunir as pessoas e mostrar uma das possibilidades de uso da Internet, já que não existe cinema na região.”

Outra comunidade do projeto é Milho Verde que, com aproximadamente mil habitantes despontou, há poucos anos, como ponto turístico em Minas Gerais, devido à sua beleza natural com várias cachoeiras, montanhas e formações rochosas. O gestor local acredita que o programa é dirigido especificamente para a comunidade e para demonstrar isso, pesquisava na Internet um sistema de fogão solar com a idéia de aproveitar os recursos naturais da região, gerando economia. Pode-se perceber nessa manifestação que o gestor consegue exteriorizar o seu entendimento sobre a função do telecentro comunitário. $\mathrm{O}$ uso da tecnologia e a possibilidade de acesso às informações direcionados para a comunidade - agregando recursos e facilidades da região, gerando benefícios para todos, criando oportunidades de trabalho, alavancando inovação, enfim, provocando mudanças de forma sustentável - vai de encontro aos objetivos do projeto e em consonância ao referencial teórico que embasou a pesquisa.

O telecentro de Tombadouro foi instalado na sede do Grupo de Produtores Rurais que desenvolve várias atividades com a população. De acordo com a gestora local, o interesse das pessoas mais jovens pelo uso da Internet é trabalho e pesquisa escolar e, para os mais velhos, a busca "é por fotos das cidades onde os filhos foram trabalhar", referindo-se aos jovens que perderam o emprego nas fábricas desativadas de farinha e rapadura. As voluntárias entrevistadas manifestaram o interesse de criar um curso de computação em que elas "pudessem formar novos voluntários e dar certificado".

Rodeador é uma comunidade com cerca de mil habitantes e vários trabalhos realizados são desenvolvidos pela Associação de Trabalho Mestre Luíza, fundada em 1996. E foi pelo esforço da Associação que se conseguiu a implantação da estrutura do que é hoje o telecentro. Dentre as comunidades do projeto piloto, essa é a que apresenta mais recursos computacionais, contando com nove computadores. O Gemas da Terra se uniu à iniciativa com o programa de acesso à Internet, instalando a antena de satélite e capacitando os voluntários. O público mais freqüente são os alunos do segundo grau que estudam em Monjolos, sede do município, distante 12 quilômetros e que se deslocam para Rodeador para usar a estrutura, principalmente à noite.

Em Rodeador, a gestora ressaltou que "as pessoas buscam informações variadas: receitas, novelas, previsão do tempo, resultado de loteria, extrato bancário e até receita de pinha." Destaca-se, novamente, uma possibilidade de uso dos recursos disponibilizados pela estrutura do telecentro, alinhados com os objetivos do projeto. Por toda a região de Rodeador pode-se encontrar a pinha, uma fruta que nasce e se desenvolve sem necessidade de maiores cuidados no seu cultivo, já fazendo parte do calendário da cidade a Festa da Pinha, que ocorre entre os meses de março e abril. Uma forma de desenvolvimento da comunidade local é a exploração desse recurso natural, encontrado em abundância, pelo uso da pesquisa de informações para seu beneficiamento, técnicas de embalagem, alternativas de utilização, criação de mercados e canais para escoar a produção, tendo o acesso proporcionado pelo telecentro à informação de utilidade.

Outra iniciativa apresentada por uma voluntária é a busca de informações para se criar um curso pré-vestibular na cidade. Observando a movimentação dos alunos do segundo grau provenientes de Monjolos, buscou-se o apoio de uma organização não-governamental para a criação de curso pré-vestibular na intenção de usar os recursos disponíveis para a geração de trabalho e renda na própria comunidade.

As idéias que despontam como o fogão solar, a criação de um curso pré-vestibular e criar um cinema ao ar livre na praça são manifestações claras de transformações de estruturas. Tais 
percepções foram abalizadas a partir de entrevista com o gestor de São Gonçalo do Rio das Pedras na qual destacava que "o movimento de inclusão social passa pela inclusão digital e as tecnologias vêm acelerando esse processo". E completava dizendo que "a inclusão digital deve ser um dos meios de inclusão social, pois ela permite a busca dos direitos sociais, da cidadania e resgata a auto-estima". O programa demonstra compreender que a tecnologia será insuficiente se não aplicadas em toda a sua potencialidade e diversidade proporcionada pelos canais de demanda e se as informações conduzidas não tiverem um uso efetivo.

A inclusão de segmentos marginalizados da população brasileira inicia-se pela percepção das potencialidades do telecentro quando agregado a sistemas informacionais, ajudando a romper a cadeia de reprodução de pobreza. De simples consumidores digitais passam a criadores, com inteligência diferenciada por especificidades informacionais.

\section{Conclusão}

Emerge a demanda por políticas públicas, coordenadas e integradas pelos diferentes atores que possam contemplar a amplitude desta questão. No nosso entender, não bastam políticas que destaquem a disponibilização de infra-estrutura tecnológica. $\mathrm{O}$ simples acesso e a posse de um acervo de informações não garantem a sustentabilidade social. Torna-se cada vez mais importante a capacidade de compreender e dar sentido a este universo de informações; sentido este que não tem como ser dissociado do arcabouço cultural do indivíduo, das organizações e da comunidade. É preciso contextualizar as informações, transformá-las em conhecimento, retrabalhá-las, para se alcançar a liberdade de se incluir. A descrição de estrutura de acesso e armazenamento de dados em meio digital não é suficiente para a inserção na sociedade do conhecimento. É preciso mais: a descrição estável e centralizada do significado desses dados organizados em torno de um esquema conceitual que é único e, por isto mesmo, tácito.

Faz-se necessário agregar políticas e programas de inclusão digital e sem reducionismos, construir a ponte que conduz à sociedade do conhecimento. Para esta engenharia o cálculo é feito sobre o entendimento de que informação, cultura e conhecimento não são somente uma questão de inovação, de modernidade. Como entende Benkler (2003), são muito mais uma questão de liberdade, pelo respeito às individualidades. Acima de tudo, necessita-se de uma precisão conceitual entre os diferentes programas e projetos de inclusão digital para que se possa então estabelecer indicadores que venham precisar os índices de inclusão para qualificarmos nossa construção de sociedade da informação.

Somente a partir da localização e precisão desses conceitos, poderemos então estabelecer um quadro mínimo de indicadores ao nível de informação, comunicação e se possível, de conhecimento, que direcionem a realidade e o nível nacional de inclusão na sociedade da informação. A evolução dos problemas informacionais e sua complexidade exigem o estabelecimento e a explicitação dos avanços e fracassos para que se alavanque o processo inclusivo.

Os estudos indicam que os governos, na intenção de suprir a carência e atraso tecnológico, vêm implementando programas de inclusão digital dando prioridade à disseminação da tecnologia com a instalação de computadores conectados à Internet, de forma a democratizar o acesso. Porém, os programas governamentais não estão alinhados com uma política de informação. Os 
programas de inclusão estão distribuídos nas esferas municipal, estadual e federal e não se integram em um movimento uniforme e coeso.

Algumas organizações não-governamentais procuram suprir essa lacuna da área social e têm conseguido implantar iniciativas mais eficazes, como no exemplo apresentado. $\mathrm{Na}$ escolha de uma tecnologia livre, compartilhada e ligada a conteúdos informacionais adequados, têm avançado na diminuição da carência, conduzindo à sustentabilidade.

Sabe-se que a inclusão depende da estrutura educacional, ou seja, o instrumento mais poderoso de integração do ser humano. A universalização digital é e será, ainda por longo tempo, insuficiente. De acordo com a ONU, $70 \%$ da população do planeta não tem acesso ao telefone e que a metade sequer conhece os benefícios da luz elétrica (RIFKIN, 2001). O Brasil possui $11,4 \%$ de analfabetos e $80 \%$ não possui computadores (INSTITUTO BRASILEIRO DE GEOGRAFIA E ESTATÍSTICA, 2000).

O objetivo passa a ser o de agregar os que estão fora do processo das transformações em curso. A velocidade das transformações tem conduzido a escolhas políticas nem sempre estruturadas ou seqüenciais. O mercado muito tem influenciado na seleção dos suportes tecnológicos nem sempre adaptados às reais necessidades. Assim, o uso do software livre torna-se uma alternativa viável, possibilitando a criação de uma nova cultura, um novo paradigma, para a emancipação das sociedades mais carentes.

O programa analisado encontra-se em um estágio inicial, carente de recursos financeiros para uma melhor estruturação. Mas já apresenta os primeiros passos para o processo de transformação da comunidade rural no sentido de conquistar um lugar na sociedade da informação em busca do desenvolvimento, de forma sustentável, preservando suas características, necessidades e costumes. Reúne informações significantes, redefine por meio de práticas que incluem a diversidade:

Tais diferenças, embora acentuadas pela direção e a velocidade das transformações em curso e seus impactos sobre o aprofundamento das disparidades sócio-espaciais, não são recentes e nem características apenas da presente fase. Elas residem em processos históricos de mais longa duração, em torno dos quais foram moldadas as sociedades e sua configuração tal como hoje se apresentam, bem como gestadas as condições que estabeleceram suas distinções e desigualdades. Isto não significa, por outro lado, que tais condições, embora estruturais, sejam definitivas ou imutáveis. Ao contrário, acredita-se que existem alternativas; que é possível fazer escolhas... a ação dos Estados nacionais, principalmente se sustentados por uma ampla base social, é essencial para que se abram brechas à mudança. (ALBAGLI, 1999, p. 297).

\section{Referências}

ALBAGLI, S. Novos espaços de regulação na era da informação e do conhecimento. In: LASTRES, H. M. M.; ALBAGLI, S. (Org.). Informação e globalização na era do conhecimento. Rio de Janeiro: Campus, 1999. 
ARAÚJO, V. M. R. H. de. Sistemas de recuperação da informação: nova abordagem teóricoconceitual. Tese (Doutorado em Comunicação) - Escola de Comunicação da Universidade Federal do Rio de Janeiro, Rio de Janeiro, 1994.

AUBERT, N. Idéologie de l'urgence et perte de sens. Tarbes, 1997. Comunicação apresentada no colóquio internacional Urgence, Gestion des Crises et Décision.

AUN, M. P. Antigas nações, novas redes: as transformações do processo de construção de políticas de informação. Tese (Doutorado em Ciência da Informação) - Instituto Brasileiro de Informação em Ciência e Tecnologia/Escola de Comunicação, Universidade Federal do Rio de Janeiro, Rio de Janeiro, 2001.

Políticas públicas de informação e desenvolvimento. In: PAIM, I. (Org.). A gestão da informação e do conhecimento. Belo Horizonte: Ed. UFMG, 2003.

AUN, M. P.; ARANTES, A. M. A. C; KROEFF, R. L. Arranjos produtivos locais e sustentabilidade: políticas públicas promotoras do desenvolvimento regional e da inclusão social. Revista Alcance, Itajaí: Univali, v. 12, n. 3, p. 317-333, set./dez. 2005.

BENKLER, Y. The political economy of Commons. Upgrade: the European journal for the informatics professional, Barcelona: Novática, v. 4, n. 3, Jun. 2003. Título deste número: Open Knowledge. Disponível em:〈http://www.upgrade-cepis.org/issues/2003/3/upgrade-vIV-3.html>. Acesso em 4 mar. 2004

BORGES, M. E. N. A informação e o conhecimento na biologia do conhecer: uma abordagem cognitiva para os estudos sobre pequenas empresas. Tese (Doutorado em Ciência da Informação) - Escola de Ciência da Informação, Universidade Federal de Minas Gerais, Belo Horizonte, 2002.

DARELLI, L. E. Telecentro como instrumento de inclusão digital para o e-gov brasileiro. Florianópolis: Telesc, 2003.

DELORS, J. (Org.). Educação: um tesouro a descobrir. São Paulo: Cortez; Brasília, DF: MEC: Unesco, 2000.

GEMAS DA TERRA. Disponível em: <http://www.gemasdaterra.com.br>. Acesso em: 17 abr. 2004.

GIDDENS, A. As conseqüências da modernidade. São Paulo: Ed. Unesp, 1991.

GONZALEZ DE GÓMEZ, M. N. G. de. Novas fronteiras tecnológicas das ações de informação: questões e abordagens. Ciência da Informação, Brasília: Instituto Brasileiro de Informação em Ciência e Tecnologia, v. 3 3, n.1, p.55-67, 2004.

INSTITUTO BRASILEIRO DE GEOGRAFIA E ESTATÍSTICA. Censo 2000. Disponível em: $<$ http://www.ibge.gov.br/censo/default.php >. Acesso em: 30 mar. 2004.

INSTITUTO NACIONAL DE TECNOLOGIA DA INFORMAÇÃO. Disponível em: <http://www.iti.br/>. Acesso em: 2 abr. 2004.

JENSEN, Mike; ESTERHUYSEN Anriette. O livro de receitas do telecentro comunitário para a África: receitas para auto-sustentabilidade. Paris: Unesco, 2001. 
LASTRES, H. M. M. ; FERRAZ, J. C. Economia da informação, do conhecimento e do aprendizado. In: LASTRES, H. M. M. ; ALBAGLI, S. (Org.). Informação e globalização na era do conhecimento. Rio de Janeiro: Campus, 1999.

LEFEBVRE, A. Business networking ou "réseautage d'affaires" sur le Web pour les profissionels francophones: optimiser son réseau profissionel, grace au Web - pourquoi faire et comment bien le faire. 6nergies.net. Disponível em: <http://www.6energies.net>. Acesso em: 6 set. 2004.

MENOU, M. J. Information literacy in national information and communications technology policies: the missed dimension, information culture. Disponível em: <http://www.nclis.gov/libinter/infolitconf\&meet/papers/menou-fullpaper.pdf >. Acesso em: 12 abr. 2004. White Paper prepared for Unesco, the U.S. National Commission on Libraries and Information Science, and the National Forum on Information Literacy, for use at the Information Literacy Meeting of Experts, Prague, The Czech Republic.

MENOU, M. J., DAY, P. Developing a sense-making methodology framework for collective learning in Latin American community telecenter assessment. Nova York, 2005. Trabalho apresentado na 55th International Communication Association Annual Conference.

MONNOYER-SMITH, L. L'urgence en politique: temps d'action et temps du discours. Sciences de la société, Toulouse, n. 44, p. 63-81, mai 1998.

MOULIER-BOUTANG, Y. O Território e as políticas de controle do trabalho no capitalismo cognitivo. In: COCCO, G. (Coord.). Capitalismo cognitivo: trabalho, redes e inovação. Rio de Janeiro: DP\&A, 2003.

NÉROT, O. Social computing: evolution or revolution? Transversales, juin 2004. Disponível em: <http://grit.agence-revolutions.com/illustrations-5juin04/social_computing>. Acesso em: 5 set. 2004.

PAIM, I. ; NEHMY, R. M. Q. Questões sobre a avaliação da informação: uma abordagem inspirada em Giddens. Perspectiva em Ciência da Informação, Belo Horizonte, jul./dez. 1998.

RIFKIN, J. A era do acesso. São Paulo: Makron Books, 2001.

SANTOS, B. de S. Para uma sociologia das ausências e uma sociologia das emergências. In: SANTOS, B. de S. (Org.) Conhecimento prudente para uma vida decente: 'um discurso sobre as ciências' revisitado. São Paulo: Cortez, 2004.

SILVEIRA, S. A. da. Inclusão digital, software livre e globalização contra-hegemônica. In: SILVEIRA, S. A. da ; CASSINO, J. (Org.) Software livre e inclusão digital. São Paulo: Conrad, 2003. 